\title{
PENGEMBANGAN ALAT BANTU ARBOR UNTUK PEMBUATAN RODA GIGI PADA MESIN FRAIS VERTIKAL
}

The machining process is included in the classification of metal cutting processes, which are used to change the shape of metal or non-metallic product by cutting, peeling or separating. One of the machines used in this cutting process is a vertical type milling machine. This machine functions to make a product, one of which was a gear. The supporting equipment needed to make this gear was a vertical arbor tool. The material used in the manufacture of this product was a cast carbon steel type using the design method for manufacturing and assembly (DFMA), which began by examining and identifying needs, conceptualizing and designing products and making these products tailored to the dimensional specifications of standard and common cutter modules in the market. The results of the manufacture of this tool were directly tested for the manufacture of gears of various sizes and produced products whose deviations were within the tolerance of the measuring instrument, namely in the range 0 to $2 \%$. In addition, the von Mises stress simulation at an engine speed of $150 \mathrm{Rpm}, 450 \mathrm{Rpm}$ and $750 \mathrm{Rpm}$ and the resulting maximum stress was still below the yield limit, so it was safe to use.

Keywords: The Supporting Equipment, DFMA, Von Misses.

\section{PENDAHULUAN}

Roda gigi memiliki keunggulan terutama dalam hal perawatan dan kemudahan dalam penerapannya pada proses perakitan menjadi produk mesin yang utuh. Proses pembuatan roda gigi pada komponen bergerak umumnya banyak dilakukan dengan menggunakan mesin perkakas [1]. Mesin perkakas pada dasarnya adalah suatu mesin yang digunakan untuk memotong suatu material guna menghasilkan sebuah produk jadi maupun setengah jadi dengan dimensi dan spesifikasi tertentu, sehingga penggunaan dan pengembangan mesin ini begitu pesat, dan kegiatan dalam prosesnya disebut dengan proses pemesinan [2]. Proses ini termasuk dalam klasifikasi proses pemotongan logam, yaitu suatu proses yang digunakan untuk mengubah bentuk suatu produk dari logam dengan cara memotong, mengupas atau memisah. Akibat dari proses ini, mesin perkakas dapat digerakkan sedemikian rupa, sehingga memungkinkan terjadinya proses pemotongan material benda kerja oleh pahat potong. Terkait dengan hal tersebut, proses pembuatan roda gigi pada dasarnya menerapkan beberapa metode untuk menghasilkan sebuah produk yang tepat dan akurat. Salah satu proses pemesinan konvensional yang digunakan untuk membuat produk roda gigi adalah mesin frais. Dalam hal ini, hanya tipe horisontal yang bisa digunakan untuk membuat roda gigi, namun masih memerlukan alat pendukung lainya yaitu horizontal arbor [2]. Disamping itu, penggunaan mesin tipe horisontal ini untuk pembuatan roda giginya masih memerlukan pemasangan tool dan ketrampilan operator yang lebih lama, serta perlu dijaga stabilitas tool straightness (kelurusan alat) agar mampu berputar secara seimbang. Kestidakstabilan pemasangan tool berdampak terhadap getaran yang muncul pada mesin tersebut, sehingga mempengaruhi keluasan dari mata potong, serta kualitas kerja alat [3]. Kestabilan proses tersebut dapat direduksi dengan mengadopsi metode integrasi yang tepat yaitu melakukan simulasi persamaan dinamis efek regeneratif untuk pemodelan mesin milling dua dimensi, dengan mengintegrasikan jumlah gigi mata potongnya dan variasi kecepatan spindelnya [4], atau kualitas produk hasil dari mesin milling ini menjadi tolak ukur kepresisian dimensinya [5], sehingga rancangan dan pembuatan produk yang kurang baik akan menghasilkan sebuah produk yang cacat dan tidak terserap dipasar atau penggunanya. Untuk meningkatkan kualitas dari produk, faktor penggunaan jig dan fixture dalam proses dengan mesin frais perlu diperhatikan, karena 
ketidakpresisian alat tersebut dapat mengakibatkan penyimpangan diameter maupun kebulatan dari produk yang diproses [6,7]. Faktor lain yang menentukan diameter dan kebulatan produk adalah karena terjadinya kontak antara pahat yang berputar terhadap benda kerja, yang ditentukan berdasarkan sudut tertentu pada sumbu pahatnya [8].

Pengembangan dan perancangan alat bantu ini bertujuan untuk meningkatkan produktivitas proses produksi dengan mempertimbangkan ukuran diameter cutter modul yang ada dipasaran, mengetahui nilai rerata penyimpanagn kedalamnan potong untuk berbagai ukuran roda gigi dan mengetahui batas minimum dan maksimum nilai dari tegangan von mises. Sehingga harus dibutuhkan teknik dan metode yang tepat dalam pembuatanya. Searah dengan hal tersebut, pembuatan produk dengan volume yang besar dan kebutuhan kecepatan produksi tinggi memerlukan alat pendukung yang khusus. Desain alat pendukung selalu berkembang karena tidak ada satu alat yang mampu memenuhi seluruh proses manufaktur. Dalam perancangan dan pembuatan alat pendukung selain desain juga memperhitungkan segi keamanan dan kenyamanan kerja. Maka dari itu, perlunya dilakukan pengembangan rancangan dan pembuatan alat bantu ini untuk mencapai produktivitas proses produksi tersebut [9]. Salah satu metode untuk menguapayakan hal tersebut dalam pengembangan produk ini adalah dengan penerapan metode desain for manufacturing and assembly (DFMA). Metode ini dapat diartikan juga sebagai desain dari suatu produk atau komponen yang dapat membantu dalam suatu proses manufaktur, proses perakitan dengan komponen lain untuk menjadi suatu produk yang utuh. Disamping itu, metode ini merupakan metode yang menekankan pada perkembangan desain kearah bentuk yang paling sederhana tanpa menghilangkan keinginan dasar dan fungsi dari alat tersebut [10]. Secara umum konsep DFMA diaplikasikan dalam tahap perancangan/pendesaianan awal, prinsip ini digunakan pada tahap awal dan analisa dilakukan secara bersamaan. Dengan demikian didapatkan keuntungan dalam hal mempersingkat waktu perancangan. Bahkan, beberapa keuntungan lain dengan penggunaan konsep ini seperti yang tersaji pada diantaranya:

a) Produk yang dihasikan akan semakin baik dari segi kualitas termasuk dalam hal ini meliputi perancangan dan proses manufakturnya

b) Akan menekankan biaya yang dikeluarkan, baik itu biaya perancangan, proses pemesinan maupun biaya untuk identifikasi masalah

c) Mempercepat atau memperpendek dari alur pengerjaan yang meliputi persipan identifikasi, waktu perancangan dan waktu proses pemesinan.

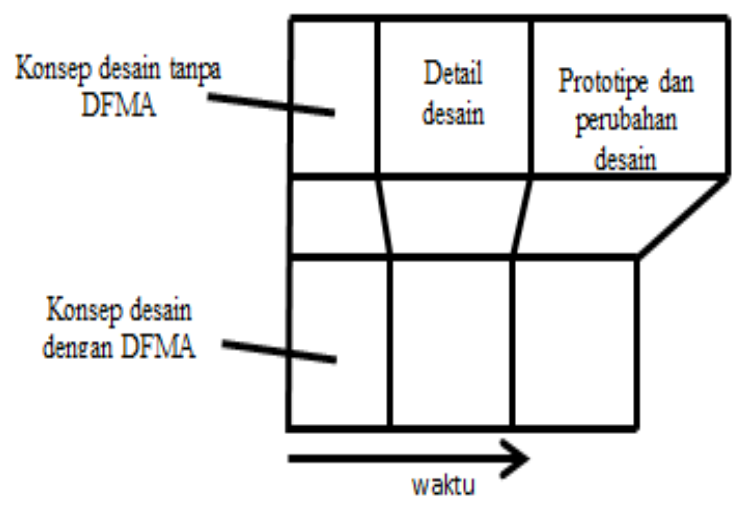

Gambar 1: Perbandingan perancangan dengan dan atau tanpa DFMA [11]

Berdasarkan gambar 1, penjelasan mengenai desain dengan menggunakan konsep DFMA relatif lebih panjang dibandingkan dengan tanpa DFMA, hal tersebut disebabkan karena lebih menitikberatkan pada ada tidaknya analisa tentang proses perakitan dan pembuatan dalam proses pemesinan. Selanjutnya, proses DFMA menjadi lebih pendek dibandingkan dengan tanpa proses DFMA [11].

\section{METODE DAN BAHAN}

Secara detail langkah-langkah penelitian ini terdiri dari tiga tahap yaitu proses identifikasi masalah, tahap konsep dan desain alat bantu serta tahap pembuatan alat pendukung yang dijelaskan pada Gambar 2 [12]. 
2.1 Identifikasi Masalah, Konsep dan Desain Alat Pendukung

a) Identifikasi masalah alat pendukung adalah melalui aspek kuantitatif yaitu dengan mengukur besar diameter cutter modul yang disesuaikan dengan besar diameter collet.

b) Proses pembuatan konsep dan desain alat pendukung untuk membuat roda gigi di mesin frais vertikal, dibantu dengan perangkat lunak

\subsection{Pembuatan Alat Pendukung}

a) Pembacaan alur rencana kerja berdasarkan urutan kerja gambar yang telah dirancang

b) Menentukan mesin perkakas apa saja yang akan digunakan berdasarkan urutan kerja gambar.

c) Pembuatan dua konsep produk alat bantu yang sudah dirancang

d) Evaluasi dan validasi pembobotan dari dua konsep produk

e) Melakukan interpretasi dengan metode design for manufacturing dan dipasangkan dengan cutter modul, kemudian di pasangkan dengan arbor mesin frais vertikal

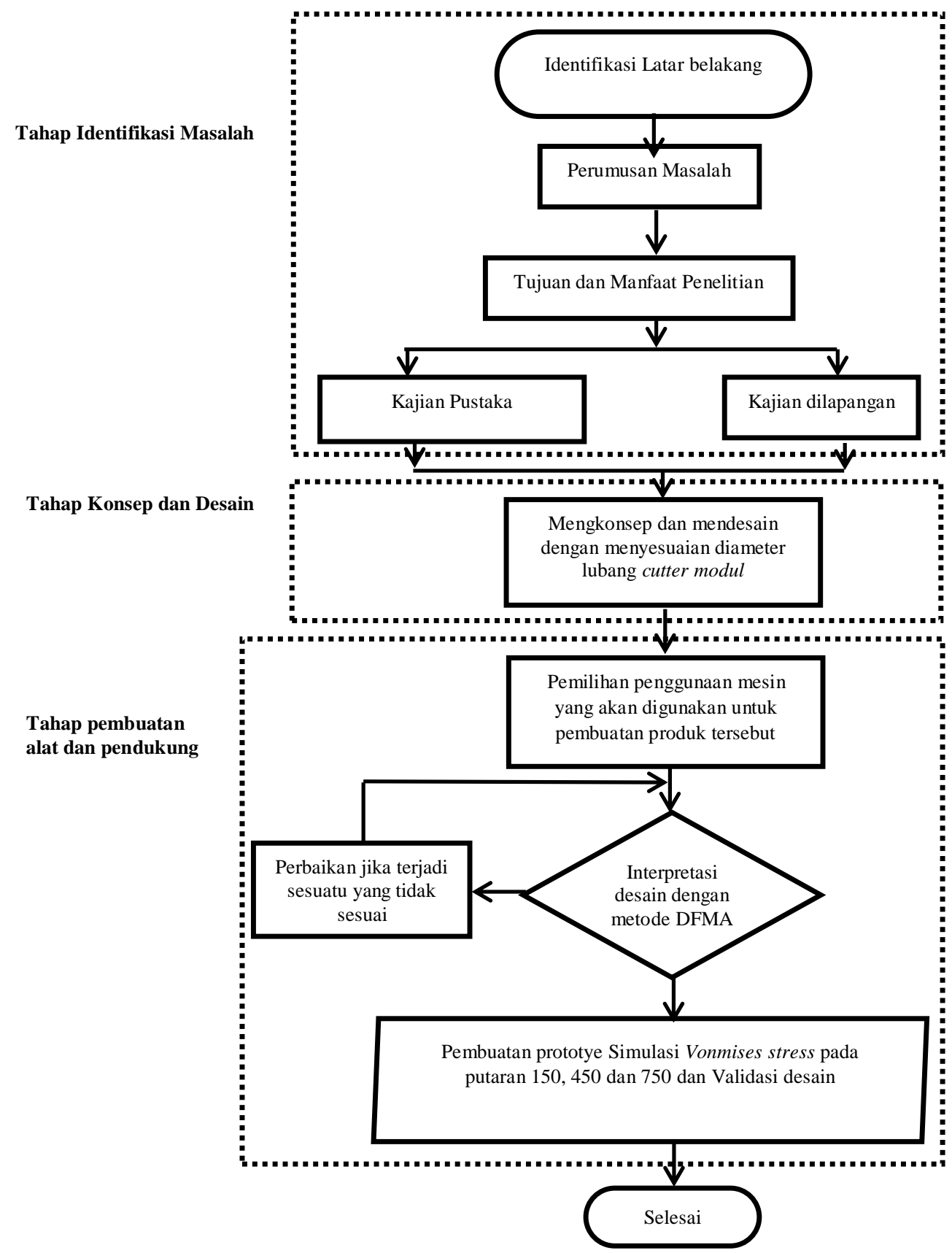

Gambar 2: Metodologi penelitian. [12] 
Peralatan Penelitian yang digunakan pada penelitian ini meliputi mesin bubut, mesin drilling, mesin gerinda, mesin frais dan mesin gergaji. Sedangkan untuk bahan penelitian yang digunakan adalah Cast Carbon Steel dengan dimensi raw material adalah Ø $60 \mathrm{~mm}$ x $120 \mathrm{~mm}$.

\section{HASIL DAN DISKUSI}

\subsection{Konsep dan Rancangan Desain}
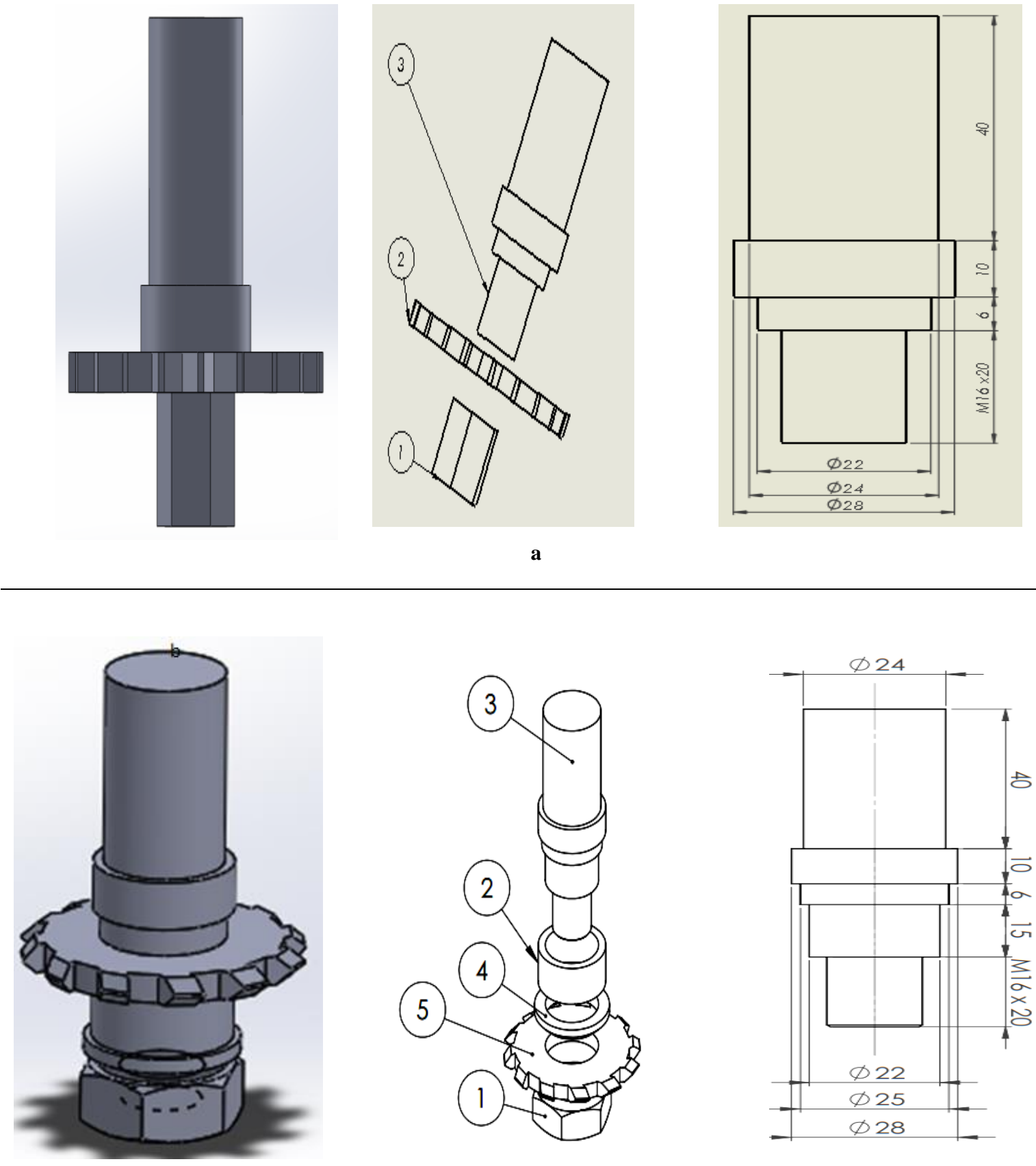

b

Gambar 3: (a) Desain rancangan awal, (b) Desain rancangan baru. 
Konsep desain dilakukan dengan menggunakan bantuan software komputer seperti yang disajikan pada gambar 3(a) dan (b) dan rancangan desain dilakukan sebanyak dua kali dengan mempertimbangkan aspek kegunaan yang didasarkan dari jenis diameter lubang pada cutter modul yang umum dipasaran serta dilakukan evaluasi pembobotan nilai [13]. Pada gambar 3(a) hanya terdiri dari tiga komponen yaitu baut, cutter modul dan poros sedangkan pada gambar 3(b) terdiri dari lima komponen yaitu baut, bushing, poros, spacer dan cutter modul

Tabel 1: Pembobotan kriteria dengan metode perangkingan.

\begin{tabular}{|c|c|c|c|c|}
\hline \multirow{3}{*}{ KRITERIA } & \multirow{3}{*}{$\begin{array}{c}\text { ASPEK } \\
\text { TEKNISNYA }\end{array}$} & \multirow{3}{*}{$\begin{array}{l}\text { SKALA } \\
\text { BOBOT }\end{array}$} & \multicolumn{2}{|c|}{$\begin{array}{l}\text { RERATA } \\
\text { RESPONDEN }\end{array}$} \\
\hline & & & $1 \mathrm{~S} / \mathrm{D} 30$ & $1 \mathrm{~S} / \mathrm{D} 30$ \\
\hline & & & $\begin{array}{c}\text { DESAIN } \\
1 \\
\end{array}$ & $\begin{array}{c}\text { DESAIN } \\
2 \\
\end{array}$ \\
\hline \multirow[t]{2}{*}{ Fungsional } & Mudah dipakai & $1 \mathrm{~s} / \mathrm{d} 10$ & 6.933 & 7.667 \\
\hline & $\begin{array}{l}\text { Dimensi tidak terlalu } \\
\text { besar }\end{array}$ & $1 \mathrm{~s} / \mathrm{d} 10$ & 7.033 & 8.833 \\
\hline \multirow[t]{3}{*}{ Desain alat } & Mudah digunakan & $1 \mathrm{~s} / \mathrm{d} 10$ & 7.533 & 7.800 \\
\hline & $\begin{array}{l}\text { Mudah penggantian } \\
\text { komponen }\end{array}$ & $1 \mathrm{~s} / \mathrm{d} 10$ & 7.433 & 8.033 \\
\hline & $\begin{array}{l}\text { Kemudahan } \\
\text { memperoleh } \\
\text { komponen }\end{array}$ & $1 \mathrm{~s} / \mathrm{d} 10$ & 6.767 & 7.767 \\
\hline \multirow[t]{2}{*}{ Manufaktur } & Mudah diproduksi & $1 \mathrm{~s} / \mathrm{d} 10$ & 6.967 & 7.133 \\
\hline & Mudah dirakit & $1 \mathrm{~s} / \mathrm{d} 10$ & 7.867 & 7.833 \\
\hline Keamanan & Aman digunakan & $1 \mathrm{~s} / \mathrm{d} 10$ & 6.800 & 7.833 \\
\hline \multirow[t]{2}{*}{ Ergonomis } & $\begin{array}{l}\text { Ukuran tidak terlalu } \\
\text { besar }\end{array}$ & $1 \mathrm{~s} / \mathrm{d} 10$ & 7.100 & 8.300 \\
\hline & Nyaman digunakan & $1 \mathrm{~s} / \mathrm{d} 10$ & 7.333 & 7.967 \\
\hline Ekonomis & Biaya ringan & $1 \mathrm{~s} / \mathrm{d} 10$ & 8.069 & 8.000 \\
\hline Total & & & 79.836 & 87.167 \\
\hline Rangking & & & 2 & 1 \\
\hline
\end{tabular}

Kemudian konsep dari dua varian tersebut dilakukan evaluasi perancangan, perawatan dan operasi serta dilakukan pembobotan nilai. Berdasarkan evaluasi pembobotan nilai didapatkan poin untuk desain $1=$ 79.836 sedangkan desain $2=87.167$. Dengan demikian berdasarkan tabel 1 diperoleh desain nomer 2 dengan nilai pembobotan yang tertinggi. Selanjutnya setelah mendapatkan konsep terpilih melakukan pembuatan produk dengan urutan proses sesuai dengan gambar rancangan dan produk aktual beserta tahapan pembuatan alatnya seperti yang disajikan pada tabel 2 .

Tabel 2: Tahapan pembuatan alat.

\begin{tabular}{l|l|l|l}
\hline NO & DESAIN GAMBAR & PRODUK AKTUAL & $\begin{array}{c}\text { PENJELASAN DAN } \\
\text { KEGUNAAN }\end{array}$ \\
\hline 1. & $\begin{array}{l}\text { Baut pada alat ini yang } \\
\text { dibuat memiliki fungsi } \\
\text { sebagai pengunci. }\end{array}$ & Baut \\
\hline
\end{tabular}




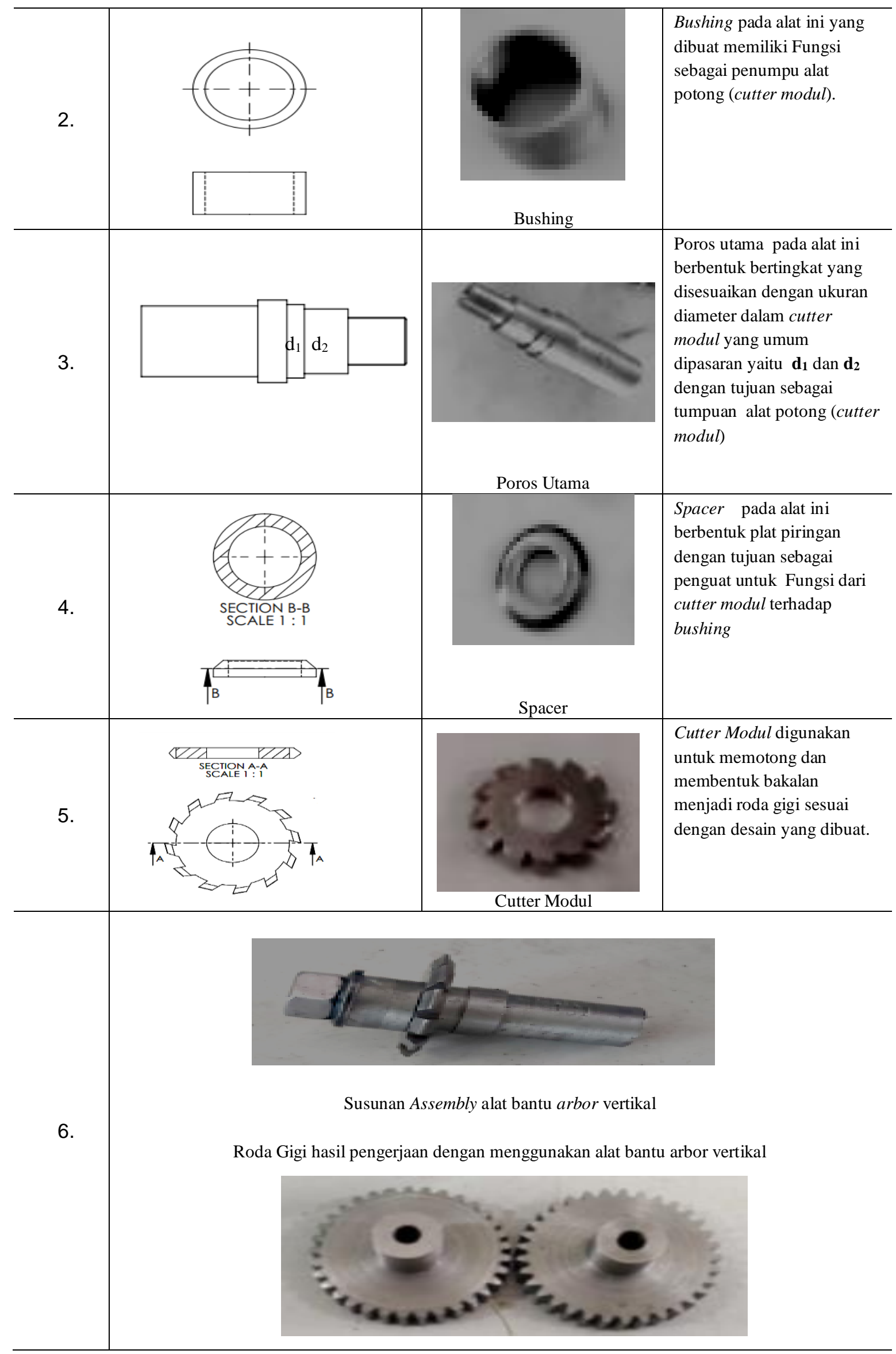




\subsection{Interprestasi Berdasarkan Proses Pembuatan Dan Perakitan}

Setelah melakukan rancangan desain alat proses selanjutnya membuat produk alat bantu tersebut sesuai dengan urutan pada tabel 2. Kemudian susunan dari lima komponen tersebut disatukan untuk dijadikan sebagai alat kesatuan yang dinamakan dengan alat bantu arbor vertikal. Adapun penjelasan secara fungsi dilapangan beberapa hal yang menjadikan desain nomer (2b) lebih unggul disebabkan karena beberapa hal berikut:

a. Produk alat bantu terdiri dari dua jenis ukuran diameter lubang dari cutter modul yang umum dipasaran, sehingga agar memudahkan pengguna maka desain dievaluasi agar dapat menampung dua jenis ukuran diameter dalam tersebut pada porosnya.

b. Produk alat bantu disisipi dengan spacer, dengan demikian saat digunakan beroperasi di mesin dengan batasan waktu tertentu dan karena adanya gesekan yang besar saat pemotongan dapat mereduksi getaran yang terjadi. Hal ini berbeda dengan desain pada (2a), yang tidak dilengkapi dengan spacer sehingga proses pengerjaanya membutuhkan kehati-hatian dan hasil produk roda gigi yang dihasilkan tidak presisi.

\subsection{Simulasi Von Mises Stress Pada Arbor Collet Mesin Frais Vertikal}

Alat ini dibuat dengan jenis material cast carbon steel yang memiliki spesifikasi sesuai pada tabel 3 . Sedangkan penggunaan parameter simulasinya adalah pada putaran $150 \mathrm{rpm}, 450 \mathrm{rpm}$ dan $750 \mathrm{rpm}$, simulasi bertujuan untuk menghindari atau meminimalisasi terjadinya kerusakan pada alat bantu ini. Disamping itu pada tabel 4 , kajian mengenai von mises untuk memberikan informasi batas nilai minimum dan maksimum luluhnya pada saat alat bantu ini dioperasikan.

Tabel 3: Spesifikasi Material Alat Bantu Arbor Vertikal.

\begin{tabular}{l|l}
\hline \multicolumn{1}{c|}{ NAMA } & \multicolumn{1}{c}{ CAST CARBON STEEL } \\
\hline Model type & Linear Elastic Isotropic \\
\hline Default failure criterion & Max von Mises Stress \\
\hline Yield strength & $2.48168 \mathrm{e}+008 \mathrm{~N} / \mathrm{m}^{2}$ \\
\hline Tensile strength & $4.82549 \mathrm{e}+008 \mathrm{~N} / \mathrm{m}^{2}$ \\
\hline Elastic modulus & $2 \mathrm{e}+011 \mathrm{~N} / \mathrm{m}^{2}$ \\
\hline Poisson's ratio & 0.32 \\
\hline Mass density & $7800 \mathrm{~kg} / \mathrm{m}^{3}$ \\
\hline Shear modulus & $7.6 \mathrm{e}+010 \mathrm{~N} / \mathrm{m}^{2}$ \\
\hline Thermal expansion coefficient & $1.2 \mathrm{e}-005 / \mathrm{Kelvin}$ \\
\hline
\end{tabular}

Tabel 4: Pengujian Von Mises Stress Untukvariasi Putaran Spindel.

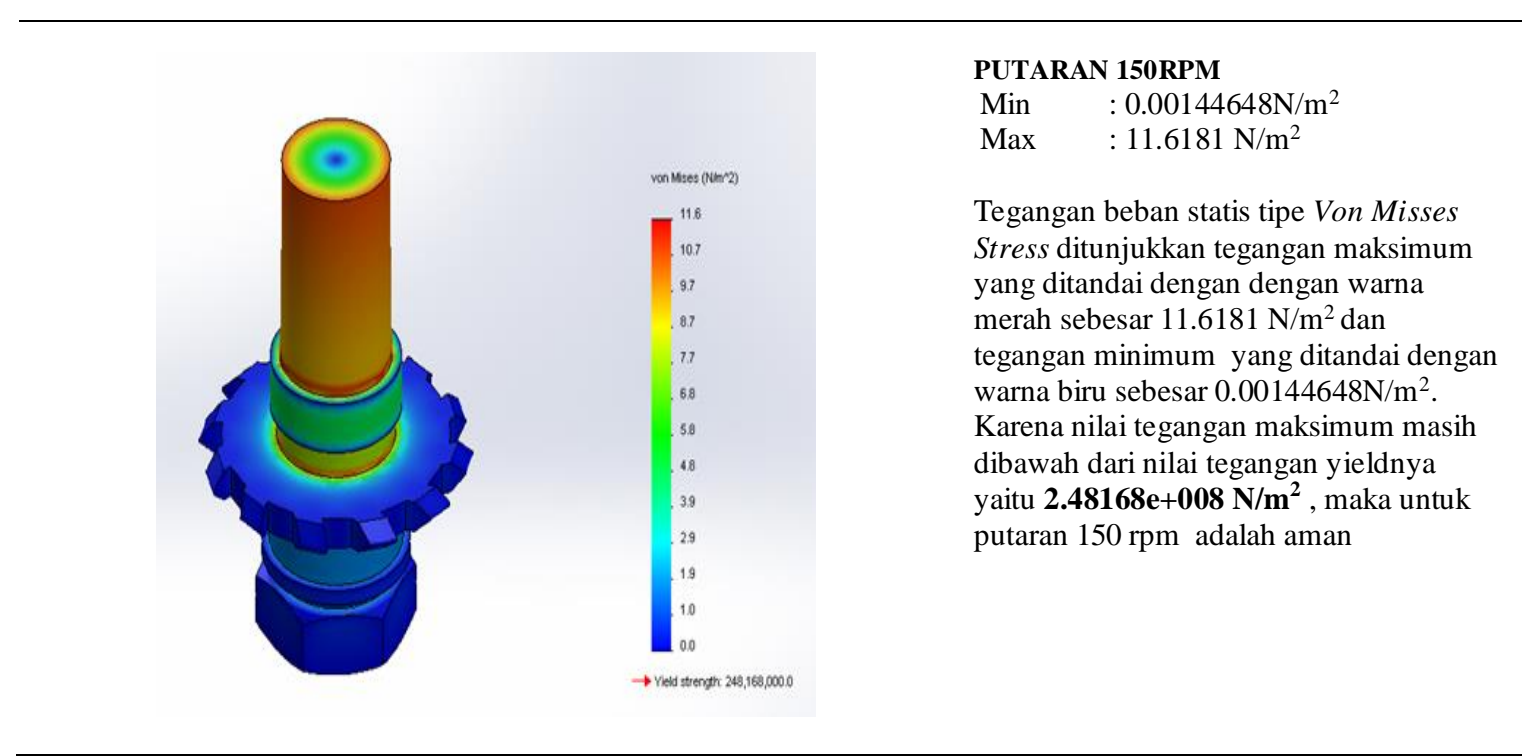




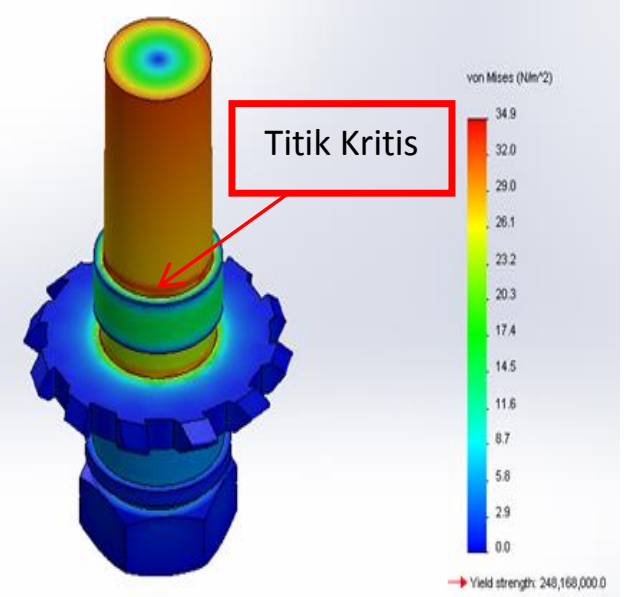

\section{PUTARAN 450RPM \\ Min $\quad: 0.00433943 \mathrm{~N} / \mathrm{m}^{2}$ \\ Max $: 34.8544 \mathrm{~N} / \mathrm{m}^{2}$}

Tegangan beban statis tipe Von Misses Stress ditunjukkan tegangan maksimum yang ditandai dengan dengan warna merah sebesar $34.8544 \mathrm{~N} / \mathrm{m}^{2}$ dan tegangan minimum yang ditandai dengan warna biru sebesar 0.00433943 $\mathrm{N} / \mathrm{m}^{2}$. Karena nilai tegangan maksimum masih dibawah dari nilai tegangan yieldnya yaitu $2.48168 \mathrm{e}+008 \mathrm{~N} / \mathrm{m}^{2}$, maka untuk putaran $450 \mathrm{rpm}$ adalah aman

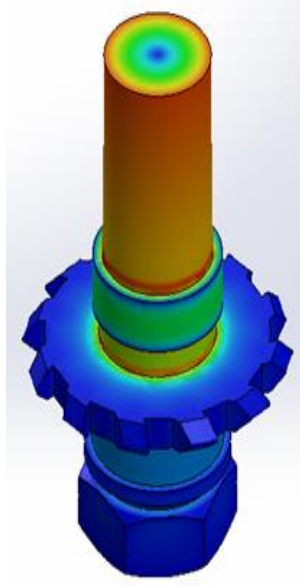

\section{PUTARAN 750RPM \\ Min $\quad: 0.00723239 \mathrm{~N} / \mathrm{m}^{2}$ \\ Max : $58.0906 \mathrm{~N} / \mathrm{m}^{2}$}

Tegangan beban statis tipe Von Misses Stress ditunjukkan tegangan maksimum yang ditandai dengan dengan warna merah sebesar $58.0906 \mathrm{~N} / \mathrm{m}^{2}$ dan tegangan minimum yang ditandai dengan warna biru sebesar 0.00723239 $\mathrm{N} / \mathrm{m}^{2}$. Karena nilai tegangan maksimum masih dibawah dari nilai tegangan yieldnya yaitu $2.48168 \mathrm{e}+008 \mathrm{~N} / \mathrm{m}^{2}$, maka untuk putaran $750 \mathrm{rpm}$ adalah aman

\subsection{Validasi Desain}

Tabel 5: Spesifikasi Desain.

\begin{tabular}{l|l|l|c}
\hline NO & \multirow{2}{*}{ KRITERIA } & ASPEK TEKNISNYA & VALIDASI \\
\hline 1 & Fungsional & Mudah dipakai & Ok \\
\hline & & Dimensi tidak terlalu besar & Ok \\
\hline \multirow{2}{*}{2} & \multirow{2}{*}{ Desain alat } & $\begin{array}{l}\text { Mudah digunakan } \\
\text { komponen }\end{array}$ & Ok \\
\cline { 3 - 4 } & & $\begin{array}{l}\text { Kemudahan memeperoleh } \\
\text { komponen }\end{array}$ & Ok \\
\hline 3 & Manufaktur & Mudah diproduksi & Ok \\
\hline 4 & & Mudah dirakit & Ok \\
\hline 5 & Keamanan & Aman digunakan & Ok \\
\hline & Ergonomis & Ukuran tidak terlalu besar & Ok \\
\hline 6 & Ekonomis & Nyaman digunakan & Ok \\
\hline
\end{tabular}


Tabel 6: Prosentase Penyimpangan Kedalaman Potong.

\begin{tabular}{c|c|c|c}
\hline \multirow{2}{*}{$\begin{array}{c}\text { JUMLAH } \\
\text { GIGI }\end{array}$} & $\begin{array}{c}\text { KEDALAMAN } \\
\text { POTONG (MM) }\end{array}$ & $\begin{array}{c}\text { RERATA HASIL } \\
\text { KEDALAMAN POTONG } \\
(\mathbf{M M})\end{array}$ & $\begin{array}{c}\text { PENYIMPANGAN } \\
(\boldsymbol{\%})\end{array}$ \\
\hline 22 & \multirow{3}{*}{3.54} & 3.54 & 0 \\
\cline { 1 - 1 } & & 3.55 & 1 \\
\cline { 3 - 4 } & & 3.56 & 2 \\
\hline
\end{tabular}

Urutan proses pembuatan roda gigi dan validasi hasil konsep serta rancangan dari alat bantu arbor vertikal ini dilakukan pengujian sebanyak tiga buah produk dengan diameter dan jumlah gigi yang berbeda namun memiliki tingkat kedalaman yang sama [14-18]. Pada tabel 5 dijelaskan mengenai beberapa aspek mengenai spesifikasi desain yang menjelaskan mengenai kriteria kegunaan dari alat bantu arbor vertikal. Berdasarkan percobaan dengan tiga buah produk yang memiliki dimensi dan jumlah gigi yang berbeda alat bantu ini dapat berfungsi dengan baik. Adapun besar penyimpangan berdasarkan dari tabel 6 dari masingmasing kedalaman untuk setiap produk dihasilkan rerata yang masih dalam toleransi kecermatan alat ukur yang yang digunakan yaitu $0,02 \mathrm{~mm}$.

\section{KESIMPULAN}

Berdasarakan dari tujuan penelitian dapat diberikan kesimpulan diantaranya sebagai berikut:

a. Penyusunan desain konsep dilakukan dalam dua kali perubahan, mengikuti kaidah DFMA dengan menyesuaikan ukuran diameter cutter modul yang ada dipasaran.

b. Pembuatan alat bantu ini langsung diujicobakan untuk pembuatan roda gigi beraneka ukuran dan dihasilkan produk yang memiliki rerata penyimpangan kedalaman potongnyaa dikisaran $0 \mathrm{~s} / \mathrm{d} 2 \%$.

c. Simulasi von mises stress pada putaran $150 \mathrm{rpm}, 450 \mathrm{rpm}$ dan $750 \mathrm{rpm}$, masing-masing menghasilkan tegangan maksimal yang masih berada dibawah batas luluhnya, sehingga variasi putaran tersebut aman untuk digunakan.

\section{PERNYATAAN TERIMAKASIH}

Ucapan terimakasih diucapkan kepada Lembaga Penelitian dan Pengabdian Masyarakat Politeknik Negeri Batam yang telah memberikan fasilitas dan bantuan biaya penelitian ini, sehingga dapat selesai dan berjalan dengan baik.

\section{DAFTAR PUSTAKA}

[1] ROCHIM, TAUFIQ.,Teknik Pemesinan, Bandung, ITB,2011

[2] YANIS, M., LEONARDO, H. 2015. "Perancangan Dan Pembuatan Alat Bantu Cekam Pada Mesin Sekrap Untuk Mengerjakan Proses Freis”, Jurnal Rekayasa Mesin, Vol 15, no. 1, 2, 2015.

[3] KAISAN, IDRIS DAN RUSIYANTO. "Pengaruh Parameter Pemotongan CNC Milling dalam Pembuatan Pocket terhadap Getaran dan Kekasaran Permukaan Pada Crankcase mesin Pemotong Rumput". Jurnal Rekayasa Mesin, Vol 11, no1, pp.41-49, 2020.

[4] DAI, Y., LI, H., XING, X., HAO, B., "Prediction of chatter stability for milling process using precise integrationmethod", Proseeeding Precision Engineering”, Vol 52, pp 152-157, 2018

[5] RAWANGWONGA, S., JAKNARIN, C.,WORAPONG,B., ROMADORN,B., "Influence Of Cutting Parameters In Face Milling Semi-SolidAA 7075 Using Carbide Tool Affected The Surface RoughnessAnd Tool Wear", Proceeding Energy Procedia, vol. 56, no. 1, pp. 448 -457, 2014

[6] JUFRI, L.SONJAYA M.,ARDI, "Rancang Bangun Alat Bantu Pelubang Platdesign Of Drilling Jig For Plat”, SNITT-Politeknik Negeri Balikpapan,vol.2, no.2, 2017.

[7] ROCHIM, TAUFIQ ,Metrologi dan Kontrol Kualitas, Bandung, ITB,2011

[8] UTSOMI, K., SHICIRI, S., SASAHARA, K., "Determining the effect of tool posture on cutting force in a turn milling process usingan analytical prediction model". International Journal of Machine Tools and Manufacture, vol.150, 2019

[9] H.,MURDIYANTO, Y., M., WIDIYARTA,I. NPG SUARDANA, "Perancangan Pahat Bor Multidiameter Jurnal Logic", vol. 14. no. 2, 2014.

[10] S. A. TANJUNG, SUWANDI, A., "Manufaktur Alat Bantu Penangkapan Ikan (Fishing Deck Machinery) Produksi dalam Negeri”, Seminar Nasional Sains dan Teknologi UMJ,2017

[11] Y. Sigit, Y. Darma, Y. Dicky, "Analisis Design for Assemblypada Mesin Roll SheeterKaret", Proceeding Seminar Nasional Tahunan Teknik Mesin XII (SNTTM XII), 2013 
[12] Susilo, A. Iksan, M. dan Subono. 2006. "Perancangan Peralatan Bantu Pembuatan Roda Gigi Lurus dan Roda Gigi Payung Guna Meningkatkan Fungsi Mesin Bubut”, Jurnal Teknik Industri Vol. 5, No. 2:1120, 2006.

[13] PRILIYANTO, C., "Perancangan Alat Bantu Cuci TanganDengan Teknologi Sederhana [PedalKaki)", Jurnal Media Aplikom, vol.12, no.01, 2020

[14] Susilo, A. Iksan, M. dan Subono. 2006. "Perancangan Peralatan Bantu Pembuatan Roda Gigi Lurus dan Roda Gigi Payung Guna Meningkatkan Fungsi Mesin Bubut”, Jurnal Teknik Industri Vol. 5, No. 2:1120, 2006.

[15] A.,P.,SAPTIAN, S.,BAGIYO, "Perancangan Ulang Alat Bantu Pengisianpasir Abrasive Steel Gritguna Meminimalkan Waktu Pengisian( Studi Kasus Pt.Safinah Blasting, Seminar Nasional Sains dan Teknologi Terapan, vol. 01, pp, 453-458,2018

[16] SUWANDI,A.,M.,R.,TEDDY, Y., FEBBRY, “Rancang Bangun Alat Bantu Panjat Pohon Kelapa Untuk Meningkatkan Produktivitas Petani Kelapa”, Prosiding SEMNASTEK, 2017

[17] LIBYAWATI, WINA, SUWANDI, AGRI, AGUSTIAN.," Rancang Bangun Teknologi Modified Atmosphere Storage (Mas) Dengan Kapasitas 4,77 m3”, Jurnal Teknologi Vol. 9, pp. 103-116, 2017.

[18] FAUZI, F., "Perencanaan Alat Bantu Pengupas Kulit Kacang Kedelai Yang Sederhana Untuk Meningkatkan Produktivitas Pengupasan Kulit Kacang Kedelaidi Pd. Sari Asri”, Jurnal Kalibrasi, vol. 12 , no.012014 